\title{
Long-Range Effectiveness of Library Use Instruction
}

\section{John Cornell Selegean, Martha Lou Thomas, and Marie Louise Richman}

If recent literature reviews are an indication, interest in bibliographic instruction is on the rise. ${ }^{1}$ However, most studies have been undertaken without sufficient emphasis on evaluating study outcomes. ${ }^{2}$ Werking suggested that the costs in dollars and staff time involved in full-scale evaluations were the main reasons for their lack in most library instruction studies. ${ }^{3}$ Brewer and Hills points out that "the absence of any generally accepted criteria perhaps helps to explain the trend in library instruction to favour evaluation according to relative standards. ${ }^{\prime 4}$

Given the current constraints on financial resources available to higher education, the need for thorough program evaluation/justification techniques is becoming more, not less, important. Library instructional research funds are becoming less available for specific, local impact programs and are being granted more and more to studies investigating such broad impact programs as standardized instructional evaluation techniques. ${ }^{5}$

Of library instruction studies with evaluations, the evaluation efforts seem to fall into one or more of three categoriesopinion surveys, knowledge testing, and actual library use observation. ${ }^{6}$ Two good examples of the use of observation for instructional evaluation can be found in works by Adams, ${ }^{7}$ and Kramer and Kramer. ${ }^{8}$ It is interesting to note that Kramer and Kramer used aggregate library circu- lation records in place of actual observation in their attempts to correlate library use and freshman persistence at their institution. The study is important in that it used objective measures for library usebook loan records-rather than relying on data provided by multiple observers such as was found in the Adams investigation.

Opinion surveys have probably seen the most use in library instruction evaluation efforts.' Studies by Lubans, Frick, Olevnik, King, and Person are representative of the range of opinion survey efforts in library instruction evaluation. ${ }^{10}$ The major drawbacks of opinion surveys are that questions tend to reflect the biases of the instrument's developers, and the data generated do not measure the effectiveness of the instruction. ${ }^{11}$

The pretest/posttest paradigm is becoming more popular in bibliographic education research, as it utilizes easily quantifiable, objective data in evaluating instructional effectiveness. Hughes and Flandreau used this technique to determine bibliographic information acquisition and retention in students at Berea College in Berea, Kentucky. ${ }^{12}$ Similarly, Wiggens, Frick, and Olevnik used the pretest/posttest research design in library instruction evaluation. ${ }^{13}$

One problem with most pretest/posttest studies is that the variables measured have very specific local application and cannot be generalized to other settings.

John Cornell Selegean is administrative analyst in the Office of Information and Systems Management, University of California-Irvine; Martha Lou Thomas is coordinator of library instruction in the reference department of the University of California Library-Irvine; and Marie Louise Richman is also an administrative analyst in the Office of Information and Systems Management, University of California-Irvine.

This study was funded by the University Research Grants for Librarians Program at the University of California, an operation instituted, monitored, and administered by the Librarians Association of the University of Califormia (LAUC). The association's persistence in obtaining research monies made possible the pursuit of this inquiry. Additionally, the advice and assistance of Dennis J. Galligani, special associate in the Office of the Vice Chancellor Academic Affairs, was invaluable throughout the project, and is gratefully acknowledged. 
That is, one institution may evaluate subsequent student performance on such nuts-and-bolts tasks as card catalog reading ability, while another school may evaluate students on general knowledge of how to research a term paper. Both colleges would be evaluating library use instruction, yet their results are not directly comparable.

Another problem with most pretest/ posttest library instruction studies is that evaluation is usually limited to short-term information retention. Thus, long-term retention of library instruction training, which may be a more effective indicator of program effectiveness, is not usually examined.

One recent study used a panel research design and multiple regression techniques to evaluate long-term library skills retention in students who took a library skills course. ${ }^{14}$ The study found that students who actively used the learned skills after the course had the best long-term skills retention. However, the study found no significant relation between library skills retention and SAT scores or eventual grade point averages.

The long-term skills retention study represents a step forward in library instruction evaluation methodology. ${ }^{15}$ The use of a measure not directly associated with a library course may provide generalizability of results not usually available in library instructional evaluation efforts.

Hardesty et al. hinted that their statistically insignificant SAT-score and gradepoint-average results might have been related to an "ecological fallacy" (other extraneous, uncontrolled variables). ${ }^{16}$ For instance, prior intellectual abilities (measured by SAT scores) were not matched for the library skills and control groups. This could have resulted in an inappropriate comparison between figurative apples and oranges instead of equivalent student groups.

Another study on the long-range effects of library use instruction on subsequent academic performance was done by P. S. Breivik. ${ }^{17}$ In this study, term paper writing scores and long-range course completion rates were found to be significantly improved for students participating in a li- brary orientation course.

The current study was conducted to evaluate the impact of the "Biblio Strategy" course on eventual student academic success, as measured by grade point average, student persistence, and graduation rate. The specific hypotheses tested were that students completing the library instruction course would have statistically higher grade point averages at graduation or upon leaving UCI than students who did not take the course and that the "Biblio Strategy" students would also have significantly higher persistence and graduation rates.

An additional goal of this study was to develop an evaluation tool that could be applied to a broad range of library use instruction courses. Such a tool could make comparisons between programs at different institutions much easier than has been previously possible.

\section{Course}

\section{METHODOLOGY}

"Biblio Strategy," a two-unit course for credit, has been offered each quarter at the University of California-Irvine (UCI) since spring 1974. Lectures on the organization of knowledge, the research process, and information resources are reinforced by assignments within the library. Completion of the course is marked by each student's compilation of an annotated bibliography of thirty citations on a subject of choice. The course is particularly recommended for those simultaneously taking classes where a research paper is required. Enrollment in a single section of "Biblio Strategy" ranges from twelve to thirty students per quarter.

\section{Subjects}

The initial population consisted of 512 undergraduates who completed the library use course between fall quarter 1975 and spring quarter 1979 . Of the 512 "Biblio Strategy" students, 278 who had no recorded SAT scores were dropped from the analysis, leaving 234 students in the final study sample. A control sample of 234 students who did not take the library instruction course was randomly selected by means of the SPSS utility SAMPLE. ${ }^{18}$ 
Three variables were used as criteria for the pairwise matching of the "Biblio Strategy" students and the members of the control group-college major, class level, and combined SAT scores. All matchings were done with data from the fall quarter of the academic year in which the "Biblio Strategy" member of each pair took the library instruction course. Students were matched exactly on college major (e.g., history majors were paired with history majors). Students were matched exactly on class level (e.g., freshmen with freshmen). Finally, student pairs were matched on combined SAT mathematics and verbal scores to within one standard deviation of each other.

\section{Outcome Variables}

Outcome variables were grade point average (measured on a 4 point scale), student persistence (in quarters of attendance after the course), and graduation rates. Grade point averages were obtained as of the end of spring quarter 1982 or when a student left UCI, whichever came first. Persistence rate was defined as the number of quarters a student remained at the university after the library use course was taken. Graduation was treated as a bipolar variable, with students either graduating or not by the end of the spring 1982 quarter.

\section{Data Analysis}

Grade point averages and student persistence rates were analyzed using stu- dents' $t$-tests for paired data. ${ }^{19}$ Graduation rate was analyzed using the chi-square statistic. $^{20}$

\section{RESULTS}

Mean variable values for study and match students can be found in table 1 . These data provide a comparison between students who took the "Biblio Strategy" course and the matched control group. The statistical significance of the results is shown in table 2. As shown, the SAT scores analysis indicated no significant difference between study and control subjects. This was expected, since the control group was selected specifically to match the study group. No analyses were done on college major or class level, since the control group was selected specifically to match the study group exactly on these variables.

Statistical analysis of the results indicated significant differences between study and control groups for the variables grade point average and persistence rate, but no significant difference was found between groups for graduation rate.

Students who completed the library use course were found to have an average of 0.15 point higher grade point averages and an average of 2.9 more quarters of attendance than the match group.

\section{DISCUSSION}

All of the library instruction evaluation studies cited in the introduction found some positive relationship between the li-

TABLE 1

MEAN VARIABLE VALUES

\begin{tabular}{lcc}
\hline \hline Variable & Biblio & Match \\
\hline SAT scores & Students & Group \\
Grade point average & 948.3 & 964.1 \\
Quarters enrolled & 2.85 & 2.70 \\
Graduation rate & 14.1 & 11.2 \\
\hline
\end{tabular}

TABLE 2

STATISTICAL ANALYSIS RESULTS

\begin{tabular}{|c|c|c|c|c|c|}
\hline Variable & Test & $\begin{array}{c}n \text { of } \\
\text { Pairs }\end{array}$ & df & $\begin{array}{c}\text { Statistic } \\
\text { Value }\end{array}$ & $\begin{array}{c}\text { 2-Tail } \\
\text { Probability }\end{array}$ \\
\hline SAT scores & $t$-test & 234 & 233 & 1.54 & $p>0.05$ \\
\hline Grade point average & t-test & 234 & 233 & 3.22 & $p>0.01$ \\
\hline Persistence rate & $t$-test & 234 & 233 & 2.21 & $p>0.05$ \\
\hline Graduation rate & $X$-square & & 1 & 3.09 & $p>0.05$ \\
\hline
\end{tabular}


brary use course and student performance or perceptions. Most of the studies, though, viewed the library use course impact as ending at the door to the library. Only a few of the recent studies investigated the broader implications of library use skills acquisition on later student academic performance.

Kramer and Kramer found that student use of the library correlated significantly with grade point average.$^{21}$ Hardesty et al. were unable to demonstrate a significant relationship between library skills acquisition and academic performance improvements, possibly due to extraneous variables. ${ }^{22}$ The fact that the current study found a statistically significant improvement in library instruction students' performance relative to that of the match sample provides confirmation of Kramer and Kramer's results.

Kramer and Kramer also determined that students who used the library tended to remain in school longer than those who did not use the library. ${ }^{23}$ Similarly, Breivik found higher course completion rates for library instruction course enrollees. ${ }^{24}$ The present study, in finding that "Biblio Strategy " students stayed at the university significantly longer than their matched counterparts, again confirmed Kramer and Kramer's, as well as Breivik's, work.

The current investigation attempted to expand the study of long-term library use skills retention through the use of graduation rates as an additional instructional effectiveness indicator. However, no significant difference was found between the "Biblio Strategy" and match groups on this variable. It is possible that the "Biblio Strategy" students, in remaining at the university longer than the match students, had artificially lowered their group graduation rate. It is also possible that the "Biblio Strategy" course, while influencing students enough to keep them at the university, might not have been enough by itself to retain students through to graduation.

The second goal of this study was to demonstrate the usefulness of long-range academic performance as a measure of the effectiveness of library instruction pro- grams. The study found that a matchedpairs analysis of long-range student performance data was an effective tool, one that compensated for the shortcomings of previous library instruction evaluation techniques. It controlled for certain forms of variance (i.e., preexisting academic abilities as measured by SAT scores, differing fields of study, and class level), which have not been accounted for in other investigations. Additionally, the use of long-range academic performance as an indicator of instructional success eliminates the instructor effect that often biases student opinion survey results.

Another advantage of this evaluation technique is that archival student performance data are usually available at colleges and universities. The information is not subject to the differing interpretations generally associated with opinion survey results or single term paper grades, but rather presents an overall picture of later student performance after library use instruction is completed.

However, the reader should be aware that this evaluation tool is not flawless. The matching control variables used here may not be the only significant contributors to academic performance. Other variables, one example being student employment while attending school, could also impact subsequent academic performance.

Further, this methodology is not meant to stand alone as a library instruction evaluation tool. It does not have the inherent sensitivity to assess the effectiveness of individual course components. It cannot, for instance, tell how well a student who took the library course uses the card catalog relative to students who did not take the course. It does not even tell how much more effectively library use instruction students use the campus library. What the methodology does point out is the apparent degree to which library use instruction benefits overall student academic performance. To the extent that this methodology provides an objective measure of the value of library use instruction, one which can be applied at many institutions of higher education, it is a useful evaluation tool. 


\section{REFERENCES}

1. H. B. Rader, "Library Orientation and Instruction-1977; An Annotated Review of the Literature," in C. A Kirkendall, ed., Improving Library Instruction: How to Teach and How to Evaluate (Ann Arbor: Pierian Pr., 1979); N. E. Gwinn, "Academic Libraries and Undergraduate Education: The CLR Experience," College \& Research Libraries 41:5-16 (Jan. 1980); R. H. Werking, "Evaluating Bibliographic Education: A Review and Critique," Library Trends 29:153-72 (1980).

2. Werking, "Evaluating Bibliographic Education"; R. R. Johnson, "Library Instruction: The Mythology of Evaluation," in R. T. Beeler, ed., Evaluating Library Use Instruction (Ann Arbor; Pierian Pr., 1975); J. Lubans, Jr., "Assessing Library Instruction," in C. A Kirkendall, ed., Directions for the Decade: Library Instruction in the 1980s (Ann Arbor: Pierian Pr., 1981).

3. R. H. Werking, "The Place of Evaluation in Bibliographic Education," in C. Oberman-Soroka, ed., Proceedings from the Southeastern Conference on Approaches to Bibliographic Instruction (Charleston, S.C.: College of Charleston Continuing Education Office, 1978).

4. J. G. Brewer and P. J. Hills, "Evaluation of Reader Instruction," Libri 26:55-66 (1976).

5. Gwinn, "Academic Libraries."

6. Werking, "Place of Evaluation."

7. M. Adams, "Effects of Evaluation on Teaching Methods," in C. A. Kirkendall, ed., Improving Library Instruction: How to Teach and How to Evaluate (Ann Arbor: Pierian Pr., 1979).

8. L. A. Kramer and M. B. Kramer, "The College Library and the Dropout," College \& Research Libraries 29:310-12 (1968).

9. Werking, "Evaluating Bibliographic Education."

10. J. Lubans, Jr., "Evaluating Attempts of Library Use Instruction Programs at the University of Colorado Libraries," in R. J. Beeler, ed., Evaluating Library Use Instruction (Ann Arbor: Pierian Pr., 1975); E. Frick, "Evaluating Student Knowledge of Facilities at the University of Colorado, Colorado Springs," in C. A. Kirkendall, ed., Improving Library Instruction: How to Teach and How to Evaluate (Ann Arbor: Pierian Pr., 1979); P. P. Olevnik, "Evaluation as a Tool for Program Development," in C. A. Kirkendall, ed., Improving Library Instruction: How to Teach and How to Evaluate (Ann Arbor: Pierian Pr., 1979); D. N. King and J. C. Ory, "Effects of Library Instruction on Student Research: A Case Study," College \& Research Libraries 42:31-37 (Jan. 1981); R. Person, "LongTerm Evaluation of Bibliographic Instruction: Lasting Encouragement," College \& Research Libraries 42:19-25 (Jan. 1981).

11. Johnson, "Library Instruction."

12. P. Hughes and A. Flandreau, "Tutorial Library Instruction: The Freshman Program at Berea College," Journal of Academic Librarianship 6, no. 2:91-94 (1980).

13. M. E. Wiggins, "Evaluation in the Instructional Psychology Model," in R. J. Beeler, ed., Evaluating Library Use Instruction (Ann Arbor: Pierian Pr., 1975); Frick, "Evaluating Student Knowledge"; Olevnik, "Evaluation as a Tool."

14. L. Hardesty; N. P. Lovrich, Jr.; and J. Mannon, "Library-Use Instruction: Assessment of the Long-Term Effects," College \& Research Libraries 43:38-46 (Jan. 1982).

15. Ibid.

16. Ibid.

17. P. S. Breivik, "Brooklyn College: A Test Case," in Open Admissions and the Academic Library (Chicago: American Library Assn., 1977).

18. N. H. Nie and others, Statistical Package for the Social Sciences (2d ed.; New York: McGraw-Hill, 1975).

19. J. P. Guilford and B. Fruchter, Fundamental Statistics in Psychology and Education (6th ed.; New York: McGraw-Hill, 1978).

20. Ibid.

21. Kramer and Kramer, "The College Library."

22. Hardesty, Lovrich, Mannon, "Library Use Instruction."

23. Kramer and Kramer," The College Library."

24. Breivik, "Brooklyn College." 

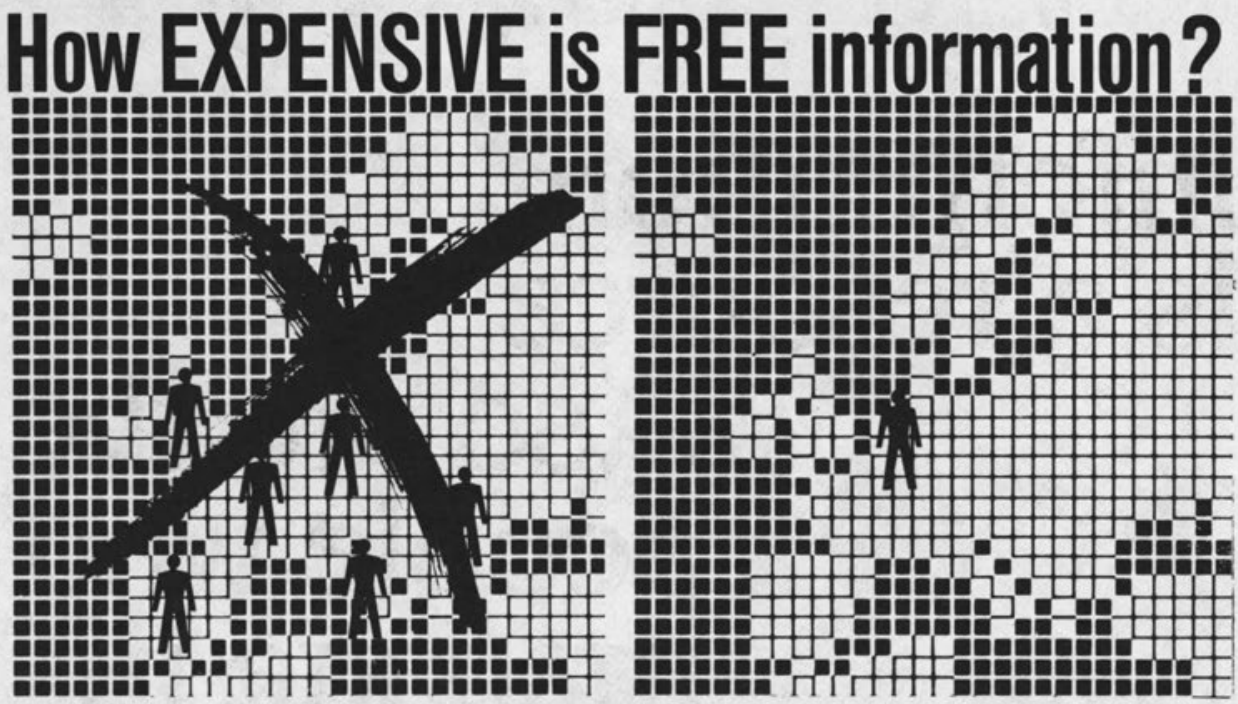

Once you concentrate your overseas subscriptions with Swets you are assured not only of fine service but also a wealth of subscription information:

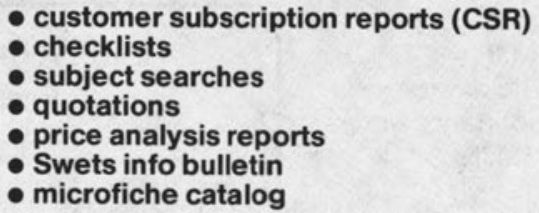

and much more. See the Information Package.

What do we charge for it? NOTHING. Since Swets introduced these accurate features our modest handling charge (if any) has become lower than before.

Ask for the Information Package and learn how reliable subscription service and an excellent information support system resulted from close cooperation between library know-how people and computer experts at Swets.

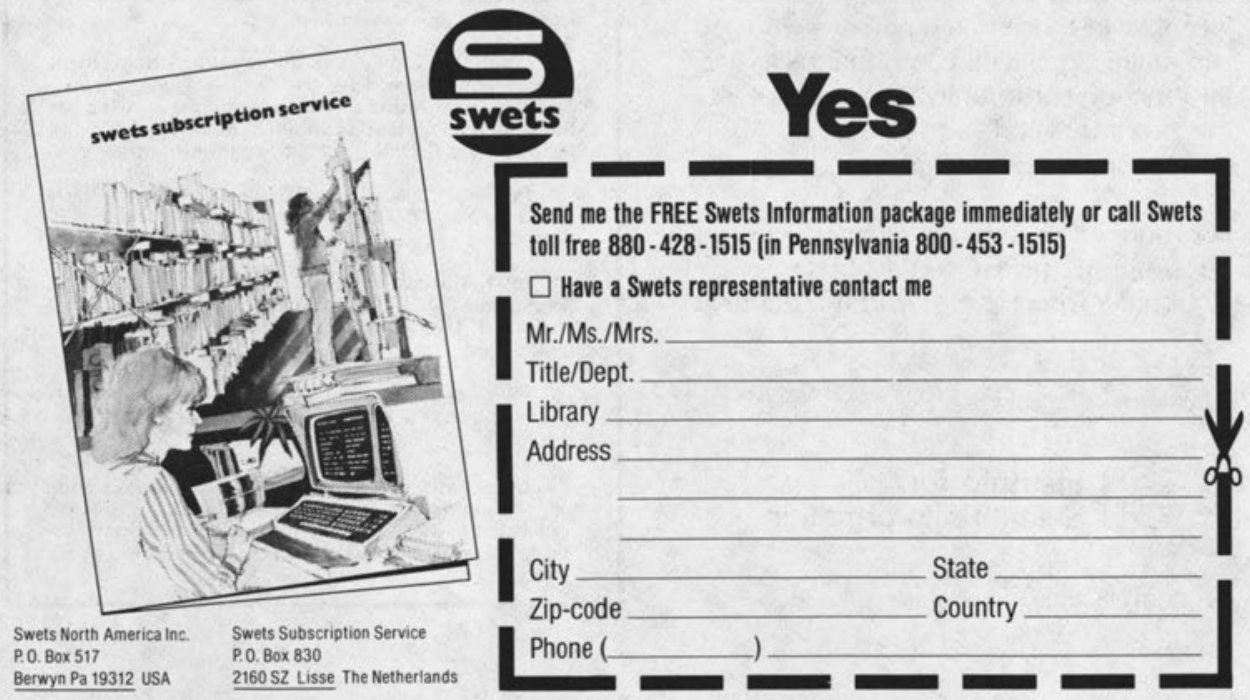




\section{Information is a resource}

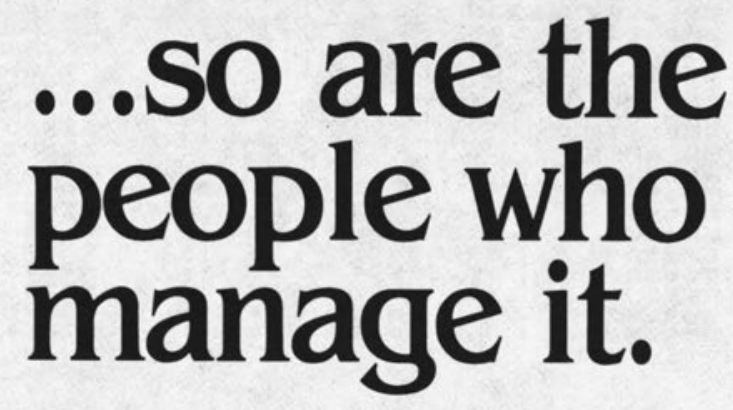

Ibrarians play a vital role in paving 1 the way toward a more wellinformed society. With your help, we gain an awareness of the importance of information and develop the skills required to deal with it effectively.

To aid your efforts, ISI offers a program of special recognition to reward and encourage advances in the fields of library and information science.

We view this program as a positive reinforcement for excellence; an incentive to those gifted persons who can make significant contributions to the information community. And most of all, this program is ISI's way of saying, "We need more people like you!"

For more information on any aspect of our program, please contact Susan McDonald, Director of Communications.

\section{吕员 Institute for}

3501 Market Street

Philadelphia, PA 19104 U.S.A.

Tel.: (215) 386-0100, Cable: SCINFO, Telex: 84-5305

\section{ISI's Program of Special Recognition}

Outstanding Information Science Teacher Award administered by the American Society for Information Science (ASIS): $\$ 500$ awarded annually to individuals who demonstrate sustained excellence in teaching information science.

Samuel Lazerow Fellowship -administered by the Association of College and Research Libraries (ACRL) $\$ 1,000$ grant honoring outstanding contributions to acquisition or technical services in an academic or research library.

Samuel Lazerow Lecture Series delivered annually at various universities with departments of libran or information science: distinguished speakers are se lected by the host universities.

Frank Bradway Rogers Information Advancement Award-administered by the Medical Library Association: $\$ 500$ awarded annually to a librarian who has made an outstanding contribution to the application of technology in delivering health sciences information.

Doctoral Dissertation Scholarship -administered by the ACRL; $\$ 1,000$ awarded annually to a student working on a dissertation on academic librarianship.

ISI Information Science Doctoral Dissertation Scholarship-administered by ASIS; $\$ 1,000$ awarded annually to a doctoral student working on his or her dissertation.

ISISpecial Libraries Association Scholarship$\$ 1,000$ given annually to a beginning doctoral candidate.

Outstanding Paper Award- $€ 250$ awarded annually in recognition of the author of the best paper published in the Joumal of Information science of the Institute of Information Scientists. Administered by the joumal. 